\title{
A synthesis of evidence on inhibitory control and auditory hallucinations based on the Research Domain Criteria (RDoC) framework
}

\author{
Johanna C. Badcock ${ }^{1,2 *}$ and Kenneth Hugdahl ${ }^{3}$ \\ ${ }^{1}$ Centre for Clinical Research in Neuropsychiatry, School of Psychiatry and Clinical Neurosciences, University of Western Australia, Crawley, WA, Australia \\ ${ }^{2}$ Clinical Research Centre, North Metropolitan Health Service-Mental Health, Perth, WA, Australia \\ ${ }^{3}$ Division of Psychiatry, Department of Biological and Medical Psychology, NORMENT Centre of Excellence (RCN \# 223273), Haukeland University Hospital, \\ University of Bergen, Bergen, Norway
}

\section{Edited by:}

John J. Foxe, Albert Einstein College of Medicine, USA

Reviewed by:

Anna Antinori, The University of

Melbourne, Australia

Raffaella Franciotti, University G.

d'Annunzio of Chieti-Pescara, Italy

*Correspondence:

Johanna C. Badcock, School of

Psychiatry and Clinical

Neurosciences, 35 Stirling Highway,

Crawley, WA 6009, Australia

e-mail: johanna.badcock@

uwa.edu.au
The National Institute of Mental Health initiative called the Research Domain Criteria (RDoC) project aims to provide a new approach to understanding mental illness grounded in the fundamental domains of human behavior and psychological functioning. To this end the RDoC framework encourages researchers and clinicians to think outside the [diagnostic] box, by studying symptoms, behaviors or biomarkers that cut across traditional mental illness categories. In this article we examine and discuss how the RDoC framework can improve our understanding of psychopathology by zeroing in on hallucinations- now widely recognized as a symptom that occurs in a range of clinical and non-clinical groups. We focus on a single domain of functioning — namely cognitive [inhibitory] control—and assimilate key findings structured around the basic RDoC "units of analysis," which span the range from observable behavior to molecular genetics. Our synthesis and critique of the literature provides a deeper understanding of the mechanisms involved in the emergence of auditory hallucinations, linked to the individual dynamics of inhibitory development before and after puberty; favors separate developmental trajectories for clinical and non-clinical hallucinations; yields new insights into co-occurring emotional and behavioral problems; and suggests some novel avenues for treatment.

Keywords: hallucinations, hearing voices, Research Domain Criteria project, inhibitory control, cognition

\section{INTRODUCTION}

The National Institute of Mental Health (NIMH) Research Domain Criteria (RDoC) project aims to provide the foundations for a new approach to the classification and treatment of mental illness (Insel et al., 2010; Cuthbert and Insel, 2013). Specifically, the RDoC initiative was designed to provide "new ways of classifying mental disorders based on dimensions of observable behavior and neurobiological measures" (National Institute of Mental Health, 2013, p. 9). As an inherently dimensional system it naturally places psychiatric disorders on a continuum with normal experience, increasing the likelihood that they will be more understandable (Bentall, 1996).

The RDoC framework is easily visualized as a matrix of columns and rows ${ }^{1}$. The rows correspond to basic functional dimensions of human behavior (termed Constructs; see Table 1), grouped —at least at the moment—into five higher level Domains: Cognitive Systems, Systems for Social Processes, Negative and Positive Valence Systems, and Arousal/Regulatory Systems. The columns, on the other hand, reflect different levels of description or Units of Analysis, ranging from genetic, molecular and cellular levels, through neural circuitry and physiology on to observable

\footnotetext{
${ }^{1}$ For full description see: http://www.nimh.nih.gov/research-funding/rdoc/ index.shtml
}

behavior and self-report. Noticeably absent from this structure are developmental and environmental perspectives relevant to mental disorder, though the intent is the matrix "will enhance the study of both areas by promoting a systematic focus on their relationship to specific circuits and functions" (National Institute of Mental Health, 2013). In short, the RDoC project provides a scaffold to rapidly organize and integrate currently available evidence (Cole, 2013), and to think beyond traditional diagnostic boundaries by studying symptoms, behaviors or biomarkers that cut across many disorders. The time is ripe, therefore, for clinicians and researchers to take on the challenge and engage in a "constructive dialog" to move things forward (Insel et al., 2010, p. 750).

Hallucinations provide a really clear example of a symptom without borders, and are intimately linked with how we interact with others (Longden, 2010; Badcock and Chhabra, 2013). Whilst habitually identified as a sign of madness and schizophrenia, at least in contemporary western society (McCarthy-Jones, 2013), they are neither disorder nor disease specific. For example, auditory hallucinations (AH) - most often in the form of hearing "voices" 2 - occur in schizoaffective and bipolar disorder

\footnotetext{
${ }^{2}$ We refer to voices and "voices" to distinguish the perception of voices in the presence or absence of an external stimulus, respectively.
} 
Table 1 | Higher order domains and associated constructs in the RDoC framework.

\begin{tabular}{|c|c|c|c|c|}
\hline Cognitive systems & $\begin{array}{l}\text { Arousal/modulatory } \\
\text { systems }\end{array}$ & Positive valence systems & Negative valence systems & Systems for social processes \\
\hline Perception & Arousal & Approach motivation & Acute threat (fear) & Affiliation and attachment \\
\hline Attention & Biological rhythms & Initial responsiveness to reward & Potential threat (anxiety) & Social communication \\
\hline Working memory & Sleep/wake & $\begin{array}{l}\text { Sustained responsiveness to } \\
\text { reward }\end{array}$ & Sustained threat & Perception and understanding of self \\
\hline Declarative memory & & Reward learning & Loss & Perception and understanding of others \\
\hline Language & & Habit & Frustrative non-reward & \\
\hline Cognitive control & & & & \\
\hline
\end{tabular}

(Shinn et al., 2012); borderline personality disorder (Slotema et al., 2012; Schroeder et al., 2013); post-traumatic stress disorder (Jessop et al., 2008); dissociative identity disorder (Dorahy et al., 2009) and disorders of anxiety and depression (Varghese et al., 2011; Wigman et al., 2012). Hallucinations are also more common than is often realized in healthy individuals in the general community, including children, adolescents, adults and the elderly with no diagnosis of mental illness (Kelleher et al., 2012a,b; Laurens et al., 2012; de Leede-Smith and Barkus, 2013). Thus, AH provide a natural opportunity to test the advantages and limitations of the RDoC approach.

A quick search of the literature shows there has been a marked rise in the number of studies on the etiology of $\mathrm{AH}$ in the last decade (Blom and Sommer, 2012; Jardri et al., 2012; Badcock et al., 2014). Unitary process accounts of AH have rapidly been displaced in favor of multiple deficit models involving a combination of perceptual, cognitive, and socio-emotional processes (Badcock, 2010; Waters et al., 2012; Stephane, 2013) which can now be mapped to fill the rows (i.e., Constructs) of the RDoC matrix. Similarly, the evidence base on $\mathrm{AH}$ includes a wide variety of analytic techniques (genetic, pharmacological, neural circuitry, neurophysiology, behavior, and phenomenology) with which we can begin to populate the columns (i.e., Units of Analysis) of the matrix. The purpose of this paper is to illustrate this approach by assimilating recent evidence concerning one single construct associated with $\mathrm{AH}$-namely Inhibitory Control (from the Cognitive Systems Domain). This choice is not meant to imply that this construct is solely or even primarily responsible for $\mathrm{AH}$; rather it was chosen because this cognitive function has been implicated in generating socially flexible behavior and a key RDOC construct linked to AH (Ford et al., in press), and because it may be regarded as a gate-keeper that allows $\mathrm{AH}$ to persist once they are elicited, and not suppressed or inhibited. Thus, a selective focus on inhibitory control allowed us to integrate literature on both normal and abnormal functioning to gain a deeper understanding of the mechanisms involved in(auditory) hallucinations, the divergent trajectories to adult mental health outcomes (Kaymaz et al., 2012; Fisher et al., 2013) and the frequent co-occurrence of other emotional and behavioral problems. Finally, both strengths and gaps in the matrix are highlighted to serve as a guide for future research. Before continuing, however, it should be noted that a similar analysis could be done for the other domains of the RDoC matrix - including other constructs from the cognitive systems domain (e.g., perception and attention), which are critically involved in $\mathrm{AH}$ and show individual variation from normal to pathological behavior (see Hugdahl et al., 2009a,b) as well as domains which have been relatively understudied in relation to $\mathrm{AH}$ (e.g., Systems for Social Processes; see Ford et al., in press).

\section{COGNITIVE SYSTEMS DOMAIN: CONSTRUCT COGNITIVE CONTROL}

The RDoC working group identified six constructs within the Cognitive Systems Domain: Cognitive Control, Perception, Attention, Declarative and Working Memory, and Language (see Table 1). Whilst each of these constructs is believed to be relevant to $\mathrm{AH}$, the first is particularly salient from the perspective of voice hearers themselves since they typically do not feel they have direct, voluntary control over their perceptions (David, 2004), which can influence their take up of effective treatments (Freeman et al., 2013). Cognitive control can be thought of as the ability to exert top-down control over task relevant processes and/or coordinate thoughts and actions to achieve a particular goal (Miller and Cohen, 2001). It relies on a superordinate neural network, including prefrontal and parietal cortices that interact with subcortical areas, components of which may be differentially activated depending on the current task demands (Niendam et al., 2012).

\section{SUBCOMPONENT-INHIBITORY CONTROL}

A fundamental aspect of cognitive control is the ability to inhibit or suppress irrelevant information or actions, so that a taskappropriate response can be made. Inhibition can take many forms and may best be described as a "family" of processes which vary in terms of what is being inhibited (e.g., thoughts or behavior) and how inhibition occurs (e.g., triggered by an external signal or driven by environmental context), each assayed by different types of task. In addition, there are large individual and age-related differences in inhibitory ability. Alternatively, defined in terms of stimuli, cognitive control is necessary in order to solve cognitive conflict (Miller and Cohen, 2001; Braver et al., 2002). Cognitive conflict would appear in situations with simultaneous presence of strong and weak stimulus elements, where the strong element causes a perceptual bottom-up response tendency, and where there is a top-down urge to process the weak element. Cognitive control is thus the use of cognitive resources to successfully manage cognitive conflict and to resolve stimulus or instruction interference (Hugdahl et al., 2009a,b). A classic 
example of a cognitive conflict that would require cognitive control as defined above is the Stroop incongruent color task (Stroop, 1935), where the strong semantic properties of the color word stimulus are in conflict with the weak ink color the word is written in. Another situation fitting this definition is the so called "forced-attention" dichotic listening task where the strong right ear stimulus is in conflict with the instruction to process the weak left ear stimulus in the dichotic listening situation (Hugdahl et al., 2009a).

The ability to generate a correct inhibitory response is present in infancy; however, the consistency of inhibitory control continues to improve throughout childhood and adolescence as evidenced across a range of inhibitory tasks (Luna et al., 2010, 2013) before declining with age (Healey et al., 2008). The brain circuitry supporting adult levels of inhibitory control centers on the prefrontal cortex (PFC), within which the ventral prefrontal cortex (VPFC) is proposed to play a primary role. Imaging studies of frontal gray matter volume reveal distinctly non-linear changes during development, with peak volume arising around 11-12 years of age (being somewhat earlier in females), followed by a rapid decline during adolescence (Gogtay and Thompson, 2010) and further decreases in volume in older adulthood (ElderkinThompson et al., 2009). In conjunction with these changes, recent evidence indicates that inhibitory processing in different subdivisions of PFC exhibits different operating characteristics before and after the onset of puberty (Luna et al., 2010). Similarly, environmental influences in these distinct stages of development appear to have different ramifications for frontal/inhibitory functioning (Hackman and Farah, 2009). In sum, this body of knowledge concerning the normative processes underlying cognitive (inhibitory) control provides a template for understanding inhibitory control impairments and the emergence of $\mathrm{AH}$, as well as yielding clues about co-occurring emotional and behavioral disorders.

\section{UNITS OF ANALYSIS: SELF-REPORT}

At the level of self-report (see Table 2) there has been a recent surge of interest in comparing the phenomenology of $\mathrm{AH}$ across different groups. Popular symptom assessment tools, such as the Psychotic Symptom Rating Scales (Haddock et al., 1999), include specific information about perceived control of AH (e.g., Can you dismiss or bring on your voices?); though a potential drawback of such questions is that they may index both the ability to suppress along with other forms of control. Nonetheless, this type of structured interview data shows that perceived control over $\mathrm{AH}$ is significantly lower in patients with psychosis or borderline personality disorder compared to healthy voice hearers (Jessop et al., 2008; Daalman et al., 2011), but is similar in patients with dissociative identity disorder and schizophrenia (Dorahy et al., 2009). Moreover, patients with schizophrenia and schizoaffective disorder report that they can differentiate their own verbal thoughts from $\mathrm{AH}$ (at least in part) on the basis of this sense of control (Hoffman et al., 2008). A notable gap in this literature concerns the lack of detailed phenomenology of hallucinatory experience in older adults; consequently it is still unclear how $\mathrm{AH}$ in younger and older adults compare. Consequently, a systematic comparison of self-reported ability to suppress hallucinations across a much broader range of diagnostic and age groups is now warranted. However, though helpful in yielding a deeper insight into voice hearers' experiences, subjective report of controllability is silent on the nature of the mechanisms involved in $\mathrm{AH}$ and does not fulfill the need for an objective biomarker or cognitive marker which could provide the foundation for a new diagnostic system for mental illness (Insel, 2013).

Adding to the problem of self-reports is the use of structured interview scales, like the Positive and Negative Syndrome Scale (PANSS: Kay et al., 1987), where data from several dimensions are merged into a common score (1-7) given by the clinician. Consequently, we are currently working on an Smartphone-based

Table 2 | Summary of key findings on cognitive/inhibitory control impairments associated with hallucinations using the RDoC matrix.

\begin{tabular}{|c|c|c|c|c|c|c|c|}
\hline \multicolumn{8}{|c|}{ COGNITIVE SYSTEMS DOMAIN } \\
\hline $\begin{array}{l}\text { Heritability } \\
\text { estimates for } \\
\text { striatal and } \\
\text { cortical DA }\end{array}$ & $\begin{array}{l}\text { Increased striatal } \\
\text { DA synthesis } \\
\text { capacity } \\
\text { Hyperexcitation } \\
\text { of Glutamate } \\
\text { Hypoexcitation } \\
\text { of GABA }\end{array}$ & $\begin{array}{l}\text { Changes in OFC } \\
\text { density and/or } \\
\text { morphology }\end{array}$ & $\begin{array}{l}\text { Superordinate } \\
\text { PFC-cingulate- } \\
\text { parietal-subcortical } \\
\text { system } \\
\text { Posterior medial } \\
\text { OFC-sub-cortical } \\
\text { loop } \\
\text { Inferior frontal } \\
\text { gyrus-anterior } \\
\text { cingulate link }\end{array}$ & $\begin{array}{l}\text { ERP 200-300 ms } \\
\text { Decreased } \\
\text { neuronal activation } \\
\text { to real voices in } \\
\text { patients with AH } \\
\text { Failure of } \\
\text { inhibition and } \\
\text { suppression of } \\
\text { "voices" }\end{array}$ & $\begin{array}{l}\text { Inhibitory } \\
\text { difficulties or } \\
\text { dysfunction } \\
\text { False alarm rates; } \\
\text { reality confusion } \\
\text { Ability to report } \\
\text { weak, left-ear } \\
\text { stimulus } \\
\text { Focused attention } \\
\text { on "real" external } \\
\text { voices }\end{array}$ & $\begin{array}{l}\text { Diminished sense } \\
\text { of control, e.g., } \\
\text { PSYRATS Item } 11 \\
\text { (Controllability of } \\
\text { "voices"). } \\
\text { Degree of } \\
\text { real-time control } \\
\text { (iDichotic: iPhone } \\
\text { app) }\end{array}$ & $\begin{array}{l}\text { Repeated } \\
\text { continuous } \\
\text { recognition } \\
\text { memory tasks } \\
\text { Forced-attention } \\
\text { dichotic listening } \\
\text { task }\end{array}$ \\
\hline
\end{tabular}

Abbreviations: AH, auditory hallucination; DA, dopamine; GABA, gamma-Aminobutyric acid; OFC, orbitofrontal cortex; PFC, prefrontal cortex; ERP, event related potential; PSYRATS, Psychotic Symptom Rating Scale. 
"app" where the patient uses the built-in slider to indicate separable aspects of the experience including: the degree to which they feel that the "voices" are coming from the inside or outside of the head (localization dimension); are negative or positive in valence (emotional dimension); and how much cognitive control they have over the "voices" (cognitive dimension). The data are stored in the iPhone/iPod for later retrieval. Such a data-driven approach to quantification of AHs has several advantages over more traditional approaches; it is patient-driven rather than therapist-driven, it is anchored in every-day life situations rather than the confines of a therapist-office, and it allows for data on day-to-day variations in $\mathrm{AH}$ parameters not possible to obtain with traditional interview scales. Whilst this is a promising start, there is a need for developing other new approaches to data collection with regard to frequency, intensity and content of AHs.

\section{UNITS OF ANALYSIS: BEHAVIOR}

In contrast, at the behavioral level of analysis considerable progress has been made in identifying the cognitive processes involved in $\mathrm{AH}$, across diagnostic boundaries (Badcock and Hugdahl, 2012a; Waters et al., 2012). Importantly, these studies indicate that $\mathrm{AH}$ in schizophrenia and in non-schizophrenia groups are associated with a specific type of impairment in cognitive (rather than motor) inhibition (see Fukushima et al., 1990; for a review Badcock and Hugdahl, 2012b) For example, Badcock and colleagues (Waters et al., 2003; Badcock et al., 2005; Paulik et al., 2007) have examined an inhibitory control process associated with $\mathrm{AH}$ in schizophrenia, and in non-clinical hallucinators using a repeated continuous recognition memory task, known as the Inhibition of Currently Irrelevant Memories task (ICIM; originally developed by Schnider, 2003). This task involves the presentation of two (or more) sequences of the same set of pictures, shown in a different order each time. In each run, participants have to indicate picture recurrences within that run, irrespective of their presentation in previous runs. So, familiarity supports correct performance on the first run, but in subsequent runs all pictures seem familiar: consequently, accurate performance in the second and later runs depends on the ability to inhibit responses (memories) that are irrelevant in the current sequence. In fact healthy individuals typically produce few errors (false alarms) on this type of task. Though somewhat similar to other source memory tasks which involve knowing which episode in the past a memory refers to, the ICIM task (and its variants) specifically involve "reality filtering," that is, the ability to distinguish whether a memory pertains to current reality or not (reviewed in Schnider, 2013).

Applying this task to patients with schizophrenia Waters and colleagues showed that the frequency of AH (but not other symptoms) was associated with an increasing number of false alarms from run to run, signaling an impairment of inhibitory control (Waters et al., 2003). Furthermore, patients with current $\mathrm{AH}$ made significantly more false alarms on this task than non-hallucinating patients, whose performance was not significantly different than healthy controls (Badcock et al., 2005). Consequently, this failure to suppress currently irrelevant memories does not appear to be a general feature of schizophrenia, rather it seem to be specifically associated with $\mathrm{AH}$. In other words, hallucinations may come about (in part) when poor inhibitory control allows representations in memory to intrude into current events ${ }^{3}$ and become confused with ongoing reality. Extending these findings beyond the diagnostic boundary of schizophrenia, Paulik and colleagues showed a similar, though somewhat milder, impairment of inhibitory control on the ICIM task in a group of healthy young adults predisposed to hallucinations, suggesting a continuity of mechanisms in clinical and non-clinical hallucinators (Paulik et al., 2007). Furthermore, follow-up studies indicated that the critical component underlying poor performance involves a difficulty intentionally suppressing unwanted cognitions already held in working memory (Paulik et al., 2008). Therefore, one possibility may be that a gradient in the severity of inhibitory control contributes to the greater frequency of hallucinations in psychosis compared to healthy voice hearers; though future research needs to show if this is a truly linear or a non-linear relationship (see Figure 1). Consequently, this specific type of inhibitory control might serve as a cognitive marker of risk for $\mathrm{AH}$ and more stringent evidence testing this proposal is now required. Of note, new findings from Badcock's group are encouraging in this regard. This latest data shows that students with high scores on the Hypomanic Personality Scale (Meads and Bentall, 2008), indexing risk for bipolar disorder, are more prone to hallucinate and produce significantly more false alarms on the ICIM task compared to those with low scores.

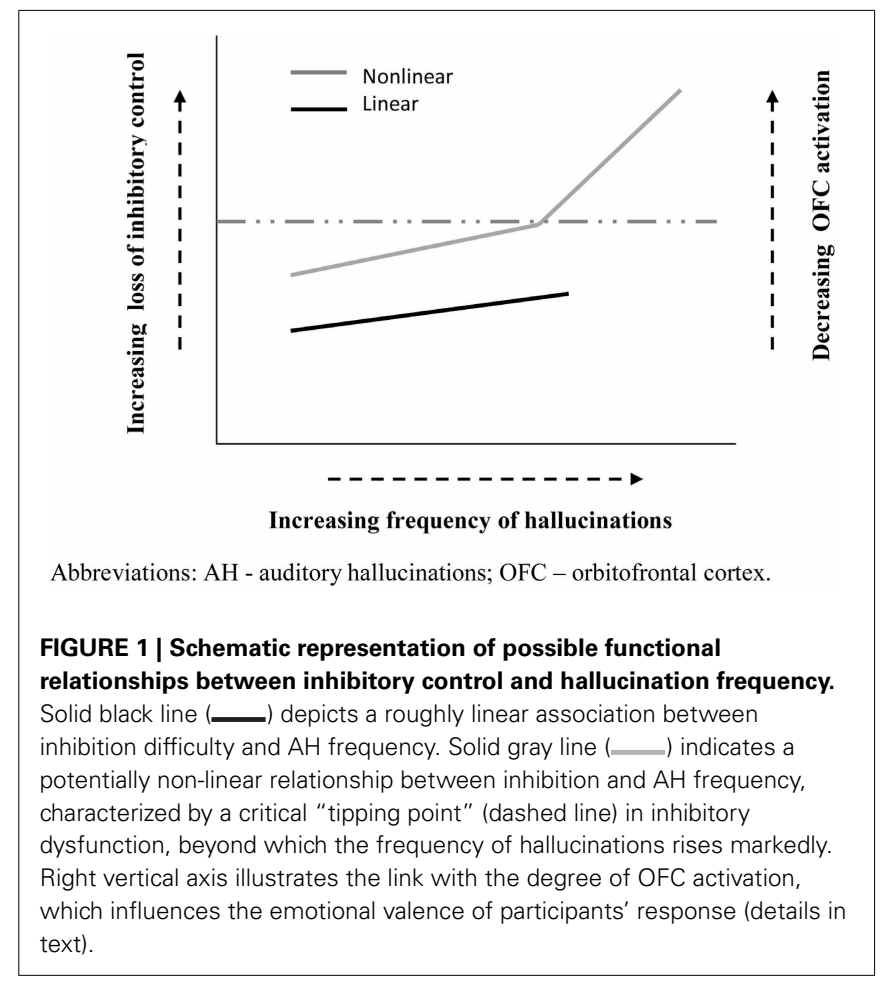

\footnotetext{
${ }^{3}$ Such intrusions are not limited to entire episodes from memory (as in traumatic replay of whole scenes) but may include intrusion of individual components of stored representations (such as words, voices etc).
} 
Clearly, future research needs to extend this approach to investigate a much broader range of clinical and non-clinical groups with $\mathrm{AH}$. In particular, it is clear that the prevalence of hallucinations increases in older adults (aged 60 years plus) (Grimby, 1998; Turvey et al., 2001) whilst inhibitory efficiency declines, yet the direct association between these factors has never been assessed. Furthermore, inhibitory dysfunction is a prominent feature in a variety of typically older patient groups, such as Parkinson's disease (Gurvich et al., 2007) and Alzheimer's disease (Amieva et al., 2004), in which hallucinations are also often reported (Scarmeas et al., 2005; Diederich et al., 2009). It would, therefore, be useful to examine the association between inhibitory control and hallucinatory experience across all of these groups using the same experimental task, in order to determine if they share a common mechanistic basis.

Since cognitive control and inhibition should be independent of sensory modalities, impairments should also be observed for auditory tasks. Hugdahl et al. (2009a,b) have used a variant of the dichotic listening task, both in normal adults and in patients with schizophrenia, to study the ability to inhibit a strong auditory stimulus being presented in one ear simultaneously with a weak stimulus presented in the other ear. The instruction is to focus attention on the weak stimulus and report it in the presence of the strong stimulus, which would require inhibitory control in order to resolve the cognitive conflict caused by the simultaneous presence of the strong and weak stimuli. In several studies, it has been shown that patients with schizophrenia in general are impaired compared to healthy controls to inhibit the strong right ear stimulus and report the weak left ear stimulus (Løberg et al., 1999), and negative correlations between the score on the PANSS hallucination item and the ability for inhibitory control in order to resolve the cognitive conflict (Hugdahl et al., 2013). The data from the dichotic listening task has also revealed that individual differences between patients with schizophrenia are larger than corresponding differences for healthy controls, something that could be related to the specific role played by $\mathrm{AH}$ in interfering with cognitive control and inhibition.

The behavioral results described so far emphasize the importance of individual differences in inhibitory control in $\mathrm{AH}$. In contrast, the role of age-related differences in inhibitory efficiency have received scant attention, yet are also likely to be important in the developmental expression of $\mathrm{AH}$ (such as the average age of onset of $\mathrm{AH}$ ) in clinical and non-clinical groups. Population-based studies show that $\mathrm{AH}$ are relatively common in childhood (Bartels-Velthuis et al., 2010; Laurens et al., 2012), but typically do not last (De Loore et al., 2011). For example, Bartels-Velthuis and colleagues reported that in young hallucinators (7-8 years) approximately three quarters had discontinued by 13 years (Bartels-Velthuis et al., 2011) -an age when frontal cortical systems have usually shifted to a mature pattern of functioning. Thus, the vast majority of hallucinations in childhood may reflect-in part-normal fluctuations in development of inhibitory control, which eventually self-correct. For others, inhibitory skills may continue to lag behind their peers and the tendency to hallucinate persists into adulthood, transitioning to psychosis in many-though not all (Fusar-Poli et al., 2013; Linscott and van Os, 2013). Critically, the timing of onset of $\mathrm{AH}$ differs in these groups: for example, in schizophrenia/schizoaffective disorder, borderline personality disorder and healthy (non-patient) hallucinators the average age of onset is around 20, 16, and 13 years, respectively, (Daalman et al., 2011; Slotema et al., 2012). A major issue for the next generation of studies will be to ascertain how the dynamics of inhibitory control before and after puberty contributes to the variation in onset and persistence of $\mathrm{AH}$ across diagnostic groups. Moreover, these different developmental trajectories undermine the notion of a single continuum underlying clinical and non-clinical $\mathrm{AH}$, in favor of separate developmental trajectories (see Figure 2).

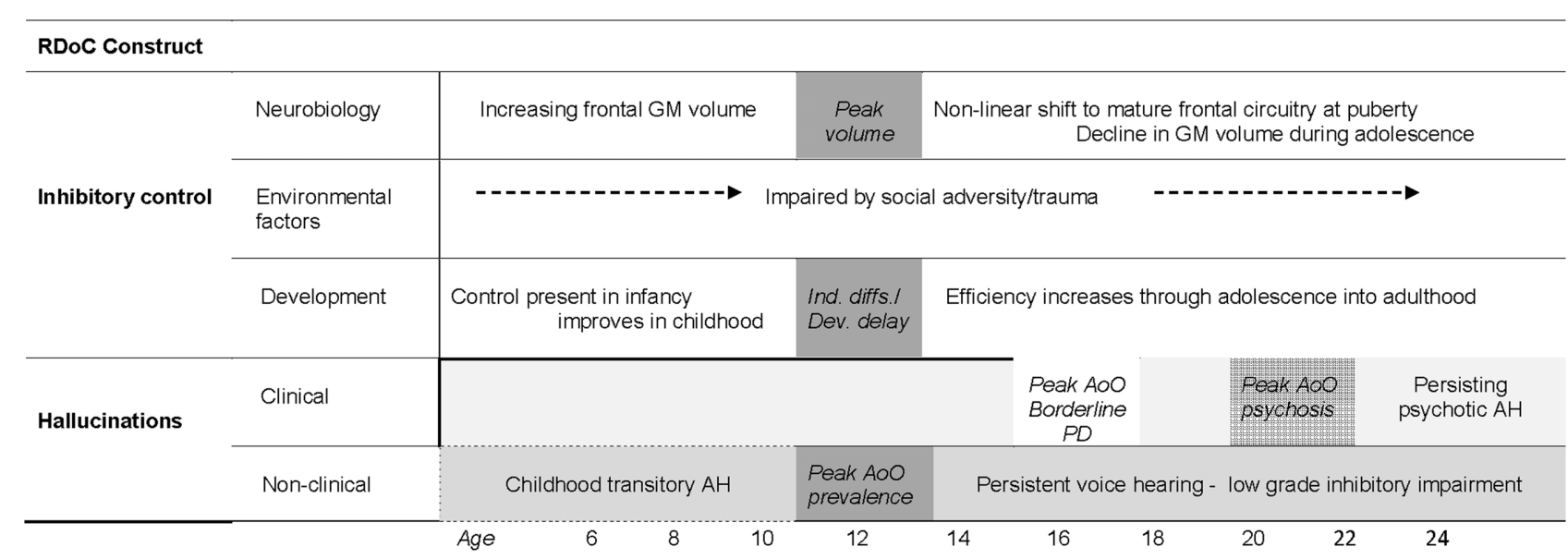

Notes: GM - Gray matter; Ind. diffs - Individual Differences; Dev. delay - Developmental delay; AoO - Age of Onset; AH - Auditory Hallucinations; PD - Personality Disorder.

FIGURE 2 | Schematic illustration of potentially separate pathways to clinical and non-clinical hallucinations linked to the dynamics of inhibitory development. 
Indeed, the growing body of evidence of differences between psychotic and non-psychotic hallucinations - in the details of their form and function-is more consistent with the presence of at least two distinct continua (Daalman et al., 2011; Badcock and Hugdahl, 2012a; Linscott and van Os, 2013).

\section{UNITS OF ANALYSIS: CELLS, CIRCUITS, AND PHYSIOLOGY}

The physiological mechanism underlying the inability to intentionally suppress currently irrelevant memories appears to depend on the orbitofrontal cortex (OFC) and related subcortical circuits (see Schnider, 2013). For example, numerous previous studies have documented a reality filtering deficit in patients with spontaneous confabulations ${ }^{4}$ due to damage in posterior medial OFC or regions directly connected to it. These patients produce a steep increase in false positive responses on the ICIM task across runs, along with an electrophysiological signature of deficient transient inhibition at 200-300 ms (see Schnider, 2003, 2008; Whelan et al., 2012). Conversely, healthy individuals who perform the task well show distinct activation of OFC (Schnider et al., 2000). These observations suggest that OFC provides a very particular type of memory control, signaling whether an activated memory relates to ongoing reality or not. The absence of evidence directly linking OFC dysfunction and hallucinations across diagnostic categories is an obvious gap in the literature. However, the OFC is a particular region of interest in psychotic disorders and in ultra-high risk cohorts (who often report brief or attenuated $\mathrm{AH}$ ) believed to be at increased risk for psychosis (Jung et al., 2012; Kubota et al., 2012; Bartholomeusz et al., 2013). For example, progressive gray matter loss in OFC and temporal regions predates the onset of psychosis in ultrahigh risk groups but not in those who do not progress to illness, (Gogtay et al., 2011) and may be a heritable component of both schizophrenia and bipolar disorder (Moran et al., 2013). These findings would be compatible with a role for OFC as a neuroanatomical marker of risk for $\mathrm{AH}$ as psychosis is developing, but this proposal is yet to be validated.

The OFC is also known to be involved in a range other functions, including social and emotional cognition (Nestor et al., 2013), which may provide new avenues for understanding $\mathrm{AH}$. For example, the degree of activation of OFC is correlated with the valence (pleasure/displeasure) of participants' emotional response: as activity decreases the unpleasantness experienced increases and pleasantness decreases (Wilson-Mendenhall et al., 2013). Thus, underlying differences in OFC activation could contribute to the prominent differences in emotional valence of $\mathrm{AH}$ in clinical (predominantly negative: less OFC activation) and non-clinical (predominantly positive: more OFC activation) groups (Daalman et al., 2011; see Figure 1). In fact, if this proposal is correct then significant differences in age of onset, frequency and valence of $\mathrm{AH}$ in psychotic and healthy voice hearers may share a common functional basis, linked to the degree of impairment in OFC circuitry. Other areas and networks which are critical for cognitive control as a way of resolving cognitive conflict include the dorsolateral PFC, and the anterior cingulate

${ }^{4}$ These clinical studies also serve as a reminder that dysfunctional inhibition is not solely associated with $\mathrm{AH}$. cortex (ACC) (Niendam et al., 2012). For example, Hugdahl's group has shown that in healthy young and old subjects the inhibitory control seen in the forced-attention dichotic listening task is mediated by the inferior frontal gyrus and anterior cingulate gyrus in the PFC (Thomsen et al., 2004). These brain regions have also been implicated in failure of inhibitory control in schizophrenia patients (Hugdahl et al., 2009b), and in particular the failure to direct attention control away from the "voices" and toward stimuli in the surrounding environment.

\section{UNITS OF ANALYSIS: MOLECULES AND GENES}

Emerging evidence from molecular genetics points to several candidate genes associated with an increased risk for hallucinations in schizophrenia or schizoaffective disorder (Sun et al., 2012), implicating multiple neurotransmitter systems, though their specific contribution to orbitofrontal reality filtering remains largely uncharted territory. The exception in this literature is that the ability to suppress currently irrelevant memories, as measured with the ICIM task, is known to be modulated by the neurotransmitter dopamine (Pihan et al., 2004). For example, healthy individuals in a hyper-dopaminergic state (induced by L-dopa) have been shown to produce a specific increase in false alarms on a challenging version of the ICIM test compared to when they received a dopamine antagonist (risperidone) (Schnider et al., 2010). Importantly, the detection of picture repetitions was not significantly influenced by L-dopa, which makes a general failure of behavioral inhibition unlikely. Indeed, Schnider (2013) has suggested that in healthy subjects a specific process may be involved in which OFC activity transiently inhibits subcortical dopaminergic neurons, signaling that a memory doesn't relate to the present reality. These observations are intriguing in view of the long-held belief that dopaminergic dysfunction is involved in the development of psychosis (Laruelle and Abi-Dargham, 1999). In fact, current theories suggest that striatal hyper-dopaminergia is centrally involved in the emergence of positive symptoms such as $\mathrm{AH}$ (Howes and Kapur, 2009) and elevated striatal dopamine synthesis capacity is consistently reported in those at ultra-high risk for psychosis (Howes et al., 2009, 2011; Egerton et al., 2013). As yet, it is unknown if similar elevations occur in other diagnostic groups experiencing $\mathrm{AH}$. However, recent data shows that dopamine synthesis capacity is not significantly different in healthy individuals with AH compared to non-hallucinating controls (Howes et al., 2013), thus the endogenous neurobiological determinants of $\mathrm{AH}$ seem to differ in those on a trajectory to psychosis vs. healthy voice hearers.

In addition to a hyper-dopaminergia as contributing to positive symptoms, it is possible that both glutamate and gammaAminobutyric acid (GABA) are involved in the elicitation of $\mathrm{AH}$ and the failure of cognitive control functions to inhibit or control the "voices" once they occur, respectively. Hyper-excitation of glutamate receptors in temporal lobe areas could be mediating findings of increased neuronal activation in these areas during states of hallucinations, at least in patients with schizophrenia (see Silbersweig et al., 1995; Dierks et al., 1999; Jardri et al., 2011; Kompus et al., 2011 for studies showing increased activation in relation to $\mathrm{AHs}$ ), possibly causing the perception of someone speaking to the patient. It is often forgotten that glutamate 
receptors are the most widely distributed receptors in the cortex (Buzsaki et al., 2007), and glutamate being the primary excitatory transmitter. This is in contrast to dopamine receptors which are relatively few in the PFC compared to the striatum and basal ganglia. Similarly, it could be hypothesized that hypo-excitation of GABA receptors, being the major inhibitory transmitter, in prefrontal areas could be a mediating factor behind a failure of inhibitory control in $\mathrm{AH}$ patients with psychosis. Consequently, we suggest the glutamate/GABA balance in temporal and frontal lobe areas may be disturbed in schizophrenia, and that the relative imbalance of glutamate and GABA activity may be mediating both the perceptual quality of AHs and the reduced resources for inhibitory control seen in these patients. Glutamate and GABA concentrations can be measured on a voxel-basis in the brain with MR spectroscopy, and although quantification of these metabolites, and in particular GABA, are currently a challenge, promising new ways how to circumvent these measurement problems are under way in several labs around the world (see Puts and Edden, 2012; Mullins et al., 2014). A glutamate hypothesis behind some of the pathophysiology seen in schizophrenia is not new (see Coyle, 2006-where abnormal functioning of glutamate receptors, and the interaction with GABA receptor inter-neurons, has been suggested to be involved in the pathophysiology of schizophrenia, and contribute to negative symptoms). We now suggest an extension of the glutamate hypothesis for schizophrenia by suggesting that the glutamate/GABA axis may play a significant role also for positive symptoms and in particular for AH (cf. Allen et al., 2012).

In drilling down through the various levels of analysis in the RDoC matrix it is easy to succumb to an exclusively biological and unidirectional explanatory model of $\mathrm{AH}$ (e.g., genes $\rightarrow$ OFC $\rightarrow$ inhibitory control $\rightarrow \mathrm{AH}$ ). So it's important that each unit of analysis is also viewed from an environmental lens. For example, there is a substantial body of evidence linking childhood trauma and social adversity with the emergence of $\mathrm{AH}$ (e.g., in psychosis and non-clinical hallucinators, Bartels-Velthuis et al., 2012; Bentall et al., 2012; Daalman et al., 2012; bipolar disorder, Hammersley et al., 2003; borderline PD, Schroeder et al., 2013). The mechanisms involved are still far from clear and undoubtedly complex. However, several recent lines of evidence suggest, for example, that striatal dopamine function is adaptive to individual environmental stressors (Martinez et al., 2010; Stokes et al., 2013) and, therefore, provides at least one plausible explanation for how trauma increases the risk for $\mathrm{AH}$ across diagnostic boundaries. Thus, based on the available data, exposure to significant social stressors should be associated with elevated DA synthesis, which in turn should lead to greater difficulty in reality filtering (i.e., inhibitory control) and a corresponding increase in the tendency to hallucinate-regardless of diagnosis. Clearly, there may be other causal pathways involved (Gracie et al., 2007; Varese et al., 2012), but this specific theoretical proposal, illustrating the potential power of the RDoC framework, is readily testable and requires further investigation. In sum, by systematically integrating environmental and biological perspectives we may get a more complete understanding of the mechanisms underlying $\mathrm{AH}$ in clinical and non-clinical groups.

\section{UNITS OF ANALYSIS: PARADIGMS}

A dimensional approach in the sense advocated by the RDoC approach would ideally allow for assessment and quantification of different cognitive domains within the same assessment paradigm. This is typically not done, and for good reasons since different cognitive constructs, e.g., perception, attention, cognitive control, traditionally require different paradigms or tests when assessing patients and healthy individuals. However, the ICM task allows for assessment of memory as well as intentional inhibition within the same task. Furthermore, since the component processes critical to $\mathrm{AH}$ are becoming clear, the next step should be to delineate its psychometric properties and optimal configuration (e.g., number of runs, target to distracter ratio) in order to assist its translation into clinical practice.

Similarly, a variant of the dichotic listening paradigm, originally labeled "forced-attention" dichotic listening by Hugdahl and Andersson (1986) allows for the successive assessment of perceptual, attention and cognitive control abilities within the same paradigm. Originally an experimental paradigm for the assessment of cerebral localization of speech perception, the forcedattention dichotic listening paradigm has become a tool for clinical assessment of a wide range of psychiatric and neurological disorders (see Hugdahl et al., 2009a,b for an overview), and would nicely fit the requirements for an assessment paradigm that cuts across cognitive domains as indicated in the RDoC. In two recent papers, Hugdahl et al. $(2012,2013)$ have shown that patients with $\mathrm{AH}$ clearly deviate from healthy controls on the three cognitive constructs-perception, attention, and cognitive control - and that this paradigm could be a valuable tool for assessing $\mathrm{AH}$ in both psychotic and non-psychotic individuals hearing "voices." There are several advantages with being able to study different cognitive constructs with a single paradigm, which is opposite to the more traditional approach of studying a single construct with different paradigms. First of all a single paradigm allows for within-construct comparisons on the same individual, i.e., differences in degree of impairment between the implicated cognitive constructs can be statistically evaluated on an individual level. Second, it allows for statistical evaluation of interaction effects between constructs and patients vs. healthy controls. Third, it allows for tight experimental control, since all stimulus parameters stay constant across the different conditions, only the instructions differ, inducing different cognitive constructs. The idea of developing novel paradigms, or utilizing existing paradigms in novel applications for the study of $\mathrm{AH}$, and also other aspects of mental disorders, that would follow from an $\mathrm{RDoC}$ approach is an interesting and promising endeavor that is to be encouraged in future research.

\section{COMORBIDITY AND DIVERGENT TRAJECTORIES}

An additional advantage that emerges from the RDoC approach is the potential to account for co-occurring symptoms routinely associated with $\mathrm{AH}$ in community and clinic settings. For example, a range of studies have shown that hallucinations during childhood often present with concurrent emotional (e.g., anxiety, depression) and behavioral (e.g., conduct problems, inattention) difficulties (Askenazy et al., 2007; Armando et al., 2010; Laurens et al., 2012), and those that persist are associated with 
an increased risk for both internalizing and externalizing disorders later in adolescence (Downs et al., 2013; Kelleher et al., 2013) as well as social dysfunction, affective disorder, substance misuse and psychosis in adulthood (Dhossche et al., 2002; Rossler et al., 2007; De Loore et al., 2011; van Rossum et al., 2011). This pattern of comorbidity and divergent trajectories is consistent with the idea that psychotic symptoms index risk for a wide range of psychopathological outcomes, not limited to psychosis (Rossler et al., 2011; Kelleher et al., 2012a,b; Fusar-Poli et al., 2013), and points to some shared or common deficits in cognitive control. Current evidence shows, for example, that in healthy individuals the OFC plays a role in emotional processing, complex decision making and adaptive social behavior (Kringelbach, 2005; Farrow et al., 2011) whilst impaired inhibitory control and hypo-activation of OFC, typical of $\mathrm{AH}$, have been linked with adolescent impulsivity and initiation of drug use (Whelan et al., 2012) as well as oppositional defiant disorder and conduct disorder (Matthys et al., 2013). We suggest that whilst several previous studies have documented the range of emotional and behavioral difficulties that occur alongside AH they have largely failed to unravel the etiological processes involved. However, by adopting the forcedattention dichotic listening task and/or the ICIM task we may now begin to explore the mechanisms underlying the complex symptom presentation and divergent trajectories associated with $\mathrm{AH}$.

\section{TREATMENT IMPLICATIONS}

Although the RDoC initiative is a classification system aimed at research (Insel et al., 2010), its different domains and dimensions may have some varied implications for treatment. Before discussing such implications, we would like to make a distinction regarding what is meant by "treatment" in general, since this is typically confused in the literature. Our argument is that depending on how one looks at "treatment," the RDoC approach may be relatively more applicable to one level of treatment than another. We would like to introduce a three-level approach to the meaning of "treatment": (1) in a classic and every-day meaning of the word, "treatment" is used in the sense of "curing" the patient. For schizophrenia this would mean the abolishment of symptoms, restoration of normal cognitive and emotional functioning, normal social and interpersonal behavior. This usage is synonymous with pharmacological treatment. (2) A second meaning is what is typically seen as the purview of psychotherapy, which aims at changing the mind-setting of the patient, to induce a different "strategy" of how to think of symptoms, other people, the environment etc. Here the patient is not "cured," but adopts a new cognitive strategy of how to meet psychological challenges. (3) A third meaning of the word is in the sense of a "training" routine, which aims at changing a specific behavioral or cognitive function, e.g., to train how to learn to shift attention away from hallucinated "voices" and to external stimuli whenever the "voices" occur: here the patient is not cured, is not taught a new general strategy, but learns how to cope with a specific symptom, whenever it occurs. We would like to suggest that focus on the different $\mathrm{RDoC}$ may have different treatment implications, operating over different time scales. For example, focus on the "Arousal/modulatory systems," including also biological rhythms and sleep-wake cycles, might have immediate implications for pharmacological treatment in the classic sense of curing the patient. Focus on "Systems for social processes" containing affiliation and attachment, social communication, and the understanding of others would have longer term implications for a psychotherapy approach to treatment, while focus on the "Cognitive systems," like attention, working memory etc. will have both short and long-term implications for a training approach to treatment. These examples are clearly not exhaustive but are included to illustrate the flexibility that the $\mathrm{RDoC}$ approach to psychiatric diagnosis allows.

Turning now to our specific focus on cognitive control we argue that a better understanding of the mechanisms involved in inhibitory processing may have clinical implications for the treatment of AH through the development of new cognitive training routines where patients can learn how to overcome loss of inhibitory control by being trained to focus attention of the weaker surrounding stimuli rather than the stronger inner "voices." For example, Soveri et al. (2013) have already shown how training to re-focus attention to the weaker sound in the dichotic listening situation can be established after 3-4 weeks of daily training. However, caution should be invoked when interpreting these findings since this study was performed on healthy individuals and such findings cannot be automatically generalized to patients. However, recent attempts to apply the same paradigm to patients experiencing AH have provided some promising results. These direct clinical attempts, using an iPod Touch version of the paradigm, involve patients being trained in their home environment for 3-4 weeks under guidance, and then being given the device to use whenever they feel the "voices" are becoming overwhelming. Although not all patients have been equally successful in increasing their ability to re-focus attention and exert cognitive control, most of the patients tested so far $(N=15)$ have reported that "training has helped me to start fighting back when the voices command me, not just be a passive follower of what they say," and "I feel more confident of myself and that I can withstand the voices" which are quotations from two patients after 4 weeks of training with the iPod Touch app. Clearly this preliminary evidence requires experimental validation, but these early clinical reports provide essential information about how patients actually experience a remediation attempt and are too often ignored in clinical research. Thus, a simple smart phone device can open up new avenues for cognitive training, which may have direct clinical utility. Similarly, a glutamate/GABA perspective on $\mathrm{AH}$ may also have clinical implications since current drug treatments primarily target dopamine $D_{1 / 2}$ receptors (Howes et al., 2012), and the development of new drug targets could be beneficial for the amelioration of AH symptoms as well. In sum, we suggest that similar novel treatment approaches may be derived from an RDoC approach, and should be explored in future research and clinical practice.

\section{CONCLUDING REMARKS, FUTURE DIRECTIONS—VERTICAL SYNERGY}

The RDoC project takes a fundamentally dimensional approach to conceptualizing mental illness and therefore has much in common with existing continuum models of AH. Our review 
significantly extends this previous work by encouraging a more integrated understanding of the biological, cognitive, and social mechanisms of inhibitory control involved in $\mathrm{AH}$, framed within an explicitly developmental perspective. It also provides new insights into the complex mix of other non-psychotic symptoms that often co-occur with $\mathrm{AH}$, and suggests a stratified way of thinking about treatment. However, in completing the RDoC matrix it is clear that a number of gaps and shortcomings in the available data on $\mathrm{AH}$ remain. Most importantly, research on $\mathrm{AH}$ in psychosis has tended to overshadow studies of the experience of hallucinations in other mental disorders, which deserve a greater focus by the research community. Similarly, whilst behavioral and physiological work on $\mathrm{AH}$ has made significant advances we note (Table 2) the dearth of evidence linking the cellular level of analysis to AH and inhibitory control, which warrants further investigation (Johnsen et al., 2013), as well as far too little attention to the impact of environmental/social factors on each separate unit of functioning. Indeed a challenge for future research will be to examine multiple units of analysis simultaneously, to probe the behavioral and psychological mechanisms of inhibitory control that drive the onset and persistence/severity of $\mathrm{AH}$.

We are aware that the focus in this article is limited to only a single domain of [cognitive] functioning, and it is clear that future research will need to determine how dysregulation in this domain interacts with other domains of functioning known to be important in $\mathrm{AH}$ (such as affective prosody deficits in the Social Process domain) or for effective cognitive performance in general (such as circadian variability from the Arousal/regulatory systems domain). An important implication arising from this analysis is that mixing participants with and without $\mathrm{AH}$ within a single study means that you will have groups that draw on different etiological mechanisms. Future research designs will benefit from linking phenomenological, neuronal and cognitive data (rows $\times$ columns) to form more homogenous clusters of hallucinatory experiences that can then be used to develop individually tailored treatments (Stephane, 2013). We would like to end this review of possible implications for research of an RDoC approach by providing an example of a comprehensive research agenda focused on $\mathrm{AH}$ that attempts to track the understanding of the underlying mechanisms in $\mathrm{AH}$ from the molecular to the clinical levels of explanation. We have labeled such an approach "vertical synergy," in the sense of utilizing knowledge from different levels of understanding in a vertical perspective, from phenomenology to molecules. A vertical synergy agenda is inspired by the ideas in the $\mathrm{RDoC}$ approach and represents a "rows $\times$ columns" matrix for advancing our knowledge of one of the most severe symptoms, $\mathrm{AH}$, in one of the most severe mental disorders, schizophrenia. Starting at the top, most empirical evidence points to the fact that the phenomenology of $\mathrm{AH}$ involves a subjective experience of hearing a "voice." This means that at the second level of explanation-the cognitive level$\mathrm{AH}$ involves a perceptual quality, and in particular the quality of a speech percept since the subjective experience is typically of a person "speaking to the patient." The perceptual nature of AH has been evidenced in the studies by Green et al. (1994), Woodruff et al. (1997), and Hugdahl et al. (2012). Granted a speech perception explanation at the cognitive level of analysis, the next question is: "what could be causing such an experience in the absence of a physical stimulus, at the neuronal level?" A reasonable first hypothesis would be to look for neuronal abnormality in brain areas connected with speech perception in the temporal lobes, moving down to a circuitry, or systems, level of explanation. Several studies have revealed faulty neuronal networks involving the temporal lobes in hallucinating patients, using EEG, PET, and fMRI (Silbersweig et al., 1995; Dierks et al., 1999; Ford et al., 2001; Hugdahl et al., 2008; see also metaanalyses in Jardri et al., 2011 and Kompus et al., 2011) confirming abnormality in especially left temporal lobe areas during AHs, which are hyper-activated during $\mathrm{AH}$ episodes. At the same time, Hugdahl et al. (2013) showed that the ability to suppress an external stimulus is negatively correlated with the frequency of $\mathrm{AH}$, pointing to a corresponding hypo-activation of prefrontal brain areas, which could explain why AHs are not inhibited once perceived. All this leads to the next level of explanation, i.e., which transmitters and receptors are dysfunctional?- causing neuronal abnormality at the circuitry level, which in turn gives rise to a virtual perceptual experience that has the phenomenological, or subjective, quality of a person "speaking" to the individual, and why this is not suppressed or inhibited. Several hypotheses have been advanced that involve both the dopaminergic and glutamatergic transmitter systems. From the hypothesis advocated by Kapur and Mamo (2003) that dopaminergic transmission is dys-regulated in schizophrenia, leading to an abnormal salience to external and internal stimuli, it could be further hypothesized that $\mathrm{AH}$ result from an abnormal salience to inner stimuli that occur spontaneously (see also Johnsen et al., 2013). Such a hypothesis can, however not explain why the "voices" are not inhibited, only how they are initiated. A more recent, untested, proposal is therefore that glutamaterigic hyper-activity may be directly or indirectly involved in the elicitation of $\mathrm{AH}$ and that these are not cognitively inhibited owing to GABAergic hypoactivity in PFC (Johnsen et al., 2013). This is a challenging hypothesis, that could be tested with MR spectroscopy from voxels in the temporal and frontal lobes, respectively, which could explain both the spontaneous excitatory initiation due to glutamate activity, and subsequent failure of inhibition due to deficient GABA activity. An RDoC approach would also require an attempt to explain $\mathrm{AH}$ at the molecular, genetic level of analysis. However, as stated by Sanjuan et al. (2013), "although a large number of studies have examined the influence of environmental risk factors... for hallucinations... the molecular genetic predispositions has received little attention" (p. 235). This also holds for a dimensional approach to hallucinations, in that no molecular study exists of the genetic basis for "hearing voices" in nonpsychotic individuals. A few studies exist that have linked genetic influences on glutamate, GABA and dopamine effects on neurons in a thalamo-cortical network, although the results are far from conclusive (Behrendt and Young, 2004). Thus, more research is needed to reveal the underlying molecular architecture behind $\mathrm{AH}$ in both clinical and non-clinical populations. Because $\mathrm{AH}$ manifest itself as such powerful behaviors, influencing the entire cognitive and emotional set-up of an individual it is reasonable to assume that such pervasive behavioral effects must have a biological cause. 


\section{REFERENCES}

Allen, P., Modinos, G., Hubl, D., Shields, G., Cachia,G., Jardri, R., et al. (2012). Neuroimaging auditory hallucinations in schizophrenia: from neuroanatomy to neurochemistry and beyond. Schizophr. Bull. 38, 695-703. doi: $10.1093 / \mathrm{schbul} / \mathrm{sbs} 066$

Amieva, H., Phillips, L. H., DellaSala, S., and Henry, J. D. (2004). Inhibitory functioning in alzheimer's disease: a review. Brain 127, 949-964. doi: 10.1093/brain/awh045

Armando, M., Nelson, B., Yung, A. R.,Ross, M., Birchwood, M., Girardi, P., et al. (2010). Psychotic-like experiences and correlation with distress and depressive symptoms in a community sample of adolescents and young adults. Schizophr.Res.119, 258-265. doi: 10.1016/j.schres.2010.03.001

Askenazy, F. L., Lestideau, K., Meynadier, A., Dor, E., Myquel, M., and Lecrubier, Y. (2007). Auditory hallucinations in pre-pubertal children. A one year followup, preliminary findings. Eur. Child Adolesc.Psychiatry 16, 411-415. doi: 10.1007/s00787-006-0577-9

Badcock, J. C. (2010). The cognitive neuropsychology of auditory hallucinations: a parallel auditory pathways framework. Schizophr.Bull. 36, 576-584. doi: $10.1093 / \mathrm{schbul} / \mathrm{sbn} 128$

Badcock, J. C., and Chhabra, S. (2013). Voices to reckon with: perceptions of voice identity in clinical and non-clinical voice hearers. Front. Hum. Neurosci.7:114. doi: 10.3389/fnhum. 2013.00114

Badcock, J. C., and Hugdahl, K. (2012a). Cognitive mechanisms of auditory verbal hallucinations in psychotic and non-psychotic groups. Neurosci. Biobehav. Rev. 36, 431-438. doi: 10.1016/j.neubiorev.2011.07.010

Badcock, J. C., and Hugdahl, K. (2012b). "Examining the continuum model of auditory hallucinations: a review of cognitive mechanisms," in Hallucinations: Research and Practice, ed J. D. Blom and I. E. C. Sommer (New York, NY: Springer Science + Business Media), 317-330.

Badcock, J. C., Laroi, F., Allen, P., and Diederen, K. (2014). Current perspectives on the mechanisms of auditory hallucinations in clinical and non-clinical populations. Frontiers Media, SA. doi: 10.3389/978-2-88919-203-8

Badcock, J. C., Waters, F. A. V., Maybery, M., and Michie, P. T. (2005). Auditory hallucinations: failure to inhibit irrelevant memories. Cogn. Neuropsychiatry 10, 125-136. doi: 10.1080/13546800344000363

Bartels-Velthuis, A. A., Jenner, J. A., van de Willige, G., van Os, J., and Wiersma, D. (2010). Prevalence and correlates of auditory vocal hallucinations in middle childhood. Br. J. Psychiatry 196, 41-46. doi: 10.1192/bjp.bp.109. 065953

Bartels-Velthuis, A. A., van de Willige, G., Jenner, J. A., van Os, J., and Wiersma, D. (2011). Course of auditory vocal hallucinations in childhood: 5year follow-up study. Br. J. Psychiatry 199, 296-302. doi: 10.1192/bjp.bp.110. 086918

Bartels-Velthuis, A. A., van de Willige, G., Jenner, J. A., Wiersma, D., and van Os, J. (2012). Auditory hallucinations in childhood: associations with adversity and delusional ideation. Psychol. Med. 42, 583-593. doi: 10.1017/S0033291711001590

Bartholomeusz, C. F., Whittle, S. L., Montague, A., Ansell, B., McGorry, P. D., Velakoulis, D., et al. (2013). Sulcogyral patterns and morphological abnormalities of the orbitofrontal cortex in psychosis. Prog. Neuropsychopharmacol. Biol. Psychiatry 44(Suppl. C), 168-177. doi: 10.1016/j.pnpbp.2013.02.010

Behrendt, R. P., and Young, C. (2004). Hallucinations in schizophrenia, sensory impairment, and brain disease: A unifying model. Behav. Brain Sci., 27, 771-787. doi: 10.1017/S0140525X04000184

Bentall, R. P. (1996). At the centre of a science of psychopathology? Characteristics and limitations of cognitive research. Cogn. Neuropsychiatry 1, 265-273. doi: 10.1080/135468096396433

Bentall, R. P., Wickham, S., Shevlin, M., and Varese, F. (2012). Do specific earlylife adversities lead to specific symptoms of psychosis? A study from the 2007 the adult psychiatric morbidity survey. Schizophr. Bull. 38, 734-740. doi: $10.1093 /$ schbul/sbs049

Blom, J. D., and Sommer, I. E. C. (2012). Hallucinations: Research and Practice. New York, NY: Springer Science + Business Media. doi: 10.1007/978-1-4614-0959-5

Braver, T. S., Cohen, J. D., and Barch, D. M. (2002). "The role of the prefrontal cortex in normal and disordered cognitive control: a cognitive neuroscience perspective," in Principles of Frontal Lobe Function, ed D. T. Stuss and R. T. Knight (Oxford: Oxford University Press), 428-448.

Buzsaki, G., Kaila, M., and Raichle, M. (2007). Inhibition and brain work. Neuron 56, 771-783. doi: 10.1016/j.neuron.2007.11.008
Cole, C. (2013). NIMH's new framework for classifying and researching psychopathology. Observer 26, 42. Available online at: http://www.psychological science.org/index.php/publications/observer/2013/july-august-13/nimhs-newframework-for-classifying-and-researching-psychopathology.html

Coyle, J. T. (2006). Glutamate and schizophrenia: beyond the dopamine hypothesis. Cell. Mol. Neurobiol. 26, 365-384. doi: 10.1007/s10571-006-9062-8

Cuthbert, B. N., and Insel, T. R. (2013). Toward the future of psychiatric diagnosis: the seven pillars of RDoC. BMC Med. 11:126. doi: 10.1186/1741-7015-11-126

Daalman, K., Boks, M. P., Diederen, K. M., de Weijer, A. D., Blom, J. D., Kahn, R. S., et al. (2011). The same or different? A phenomenological comparison of auditory verbal hallucinations in healthy and psychotic individuals. J. Clin. Psychiatry 72, 320-325. doi: 10.4088/JCP.09m05797yel

Daalman, K., Diederen, K. M., Derks, E. M., van Lutterveld, R., Kahn, R. S., and Sommer, I. E. (2012). Childhood trauma and auditory verbal hallucinations. Psychol. Med. 42, 2475-2484. doi: 10.1017/S0033291712000761

David, A. (2004). The cognitive neuropsychiatry of auditory verbal hallucinations: an overview. Cogn. Neuropsychiatry 9, 107-123. doi: 10.1080/13546800344000183

de Leede-Smith, S., and Barkus, E. (2013). A comprehensive review of auditory verbal hallucinations: lifetime prevalence, correlates and mechanisms in healthy and clinical individuals. Front. Hum. Neurosci. 7:367. doi: 10.3389/fnhum.2013.00367

De Loore, E., Gunther, N., Drukker, M., Feron, F., Sabbe, B., Deboutte, D., et al. (2011). Persistence and outcome of auditory hallucinations in adolescence: a longitudinal general population study of 1800 individuals. Schizophr. Res. 127, 252-256. doi: 10.1016/j.schres.2011.01.015

Dhossche, D., Ferdinand, R., Van der Ende, J., Hofstra, M. B., and Verhulst, F. (2002). Diagnostic outcome of self-reported hallucinations in a community sample of adolescents. Psychol. Med. 32, 619-627. doi: 10.1017/S003329170200555X

Diederich, N. J., Fénelon, G., Stebbins, G., and Goetz, C. G. (2009). Hallucinations in Parkinson disease. Nat. Rev. Neurol. 5, 331-342. doi: 10.1038/nrneurol.2009.62

Dierks, T., Linden, D. E. J., Jandl, M., Formisano, E., Goebel, R., Lanfermann, H., et al. (1999). Activation of Heschl's gyrus during auditory hallucinations. Neuron 22, 615-621. doi: 10.1016/S0896-6273(00)80715-1

Dorahy, M. J., Shannon, C., Seagar, L., Corr, M., Stewart, K., Hanna, D., et al. (2009). Auditory hallucinations in dissociative identity disorder and schizophrenia with and without a childhood trauma history: Similarities and differences. J. Nerv. Ment. Dis. 197, 892-898. doi: 10.1097/NMD.0b013e3181c299ea

Downs, J. M., Cullen, A. E., Barragan, M., and Laurens, K. (2013). Persisting psychotic-like experiences are associated with both externalising and internalising psychopathology in a longitudinal general population child cohort. Schizophr. Res. 144, 99-104. doi: 10.1016/j.schres.2012.12.009

Egerton, A., Chaddock, C. A., Winton-Brown, T. T., Bloomfield, M. A., Bhattacharyya, S., Allen, P., et al. (2013). Presynaptic striatal dopamine dysfunction in people at ultra-high risk for psychosis: findings in a second cohort. Biol. Psychiatry 74, 106-112. doi: 10.1016/j.biopsych.2012.11.017

Elderkin-Thompson, V., Hellemann, G., Pham, D., and Kumar, A. (2009). Prefrontal brain morphology and executive function in healthy and depressed elderly. Int. J. Geriatr. Psychiatry 24, 459-468. doi: 10.1002/ gps. 2137

Farrow, T. F. D., Jones, S. C., Kaylor-Hughes, C. J., Wilkinson, I. D., Woodruff, P. W. R., Hunter, M. D., et al. (2011). Higher of lower? The functional anatomy of perceived allocentric social hierarchies. Neuroimage 57, 1552-1560. doi: 10.1016/j.neuroimage.2011.05.069

Fisher, H. L., Caspi, A., Poulton, R., Meier, M. H., Houts, R., Harrington, H., et al. (2013). Specificity of childhood psychotic symptoms for predicting schizophrenia by 38 years of age: a birth cohort study. Psychol. Med.10, 1-10. doi: 10.1017/S0033291712003091

Ford, J. M., Mathalon, D. H., Kalba, S., Whitfield, S., Faustman, W. O., and Roth, W. T. (2001). Cortical responsiveness during inner speech in schizophrenia: an event-related potential study. Am. J. Psychiatry 158, 1914-1916. doi: 10.1176/appi.ajp.158.11.1914

Ford, J. M., Morris, S., Hoffman, S. I., Waters, F., McCarthy-Jones, S.,Cuthbert, B., et al. (in press). Studying hallucinations within the NIMH RDoC framework: report from the 2nd international consortium on hallucinations research. Schizophr. Bull. 
Freeman, D., Dunn, G., Garety, P., Weinman, J., Kuipers, E., Fowler, D., et al. (2013). Patients' beliefs about the causes, persistence and control of psychotic experiences predict take-up of effective cognitive behaviour therapy for psychosis. Psychol. Med. 43, 269-277. doi: 10.1017/S0033291712001225

Fukushima, J., Morita, N., Fukushima, K., Chiba, T., Tanaka, S., and Yamashita, I. (1990). Voluntary control of saccadic eye movements in patients with schizophrenic and affective disorders. J. Psychiatr. Res. 24, 9-24. doi: 10.1016/0022-3956(90)90021-H

Fusar-Poli, P., Borgwardt, S., Bechdolf, A., Addington, J., Riecher-Rossler, A., Schultze-Lutter, F., et al. (2013). The psychosis high-risk state: a comprehensive state-of-the-art review. JAMA Psychiatry 70, 107-120. doi: 10.1001/jamapsychiatry. 2013.269

Gogtay, N., and Thompson, P. M. (2010). Mapping gray matter development: implications for typical development and vulnerability to psychopathology. Brain Cogn. 72, 6-15. doi: 10.1016/j.bandc.2009.08.009

Gogtay, N., Vyas, N. S., Testa, R., Wood, S. J., and Pantelis, C. (2011). Age of onset of schizophrenia: perspectives from structural neuroimaging studies. Schizophr. Bull. 37, 504-513. doi: 10.1093/schbul/sbr030

Gracie, A., Freeman, D., Green, S., Garety, P. A., Kuipers, E., Hardy, A., et al. (2007). The association between traumatic experience, paranoia and hallucinations: a test of the predictions of psychological models. Acta Psychiatr. Scand.116, 280-289. doi: 10.1111/j.1600-0447.2007.01011.x

Green, M. F., Hugdahl, K., and Mitchell, S. (1994). Dichotic listening during auditory hallucinations in schizophrenia. Am. J. Psychiatry 151, 357-362.

Grimby, A. (1998). Hallucinations following the loss of a spouse: common and normal events amongthe elderly. J. Clin. Gerontol. 4, 65-74.

Gurvich, C., Georgiou-Karistianis, N., Fitzgerald, P. B., Millist, L., and White, O. B. (2007). Inhibitory control and spatial working memory in Parkinson's disease. Mov. Disord. 22, 1444-1450. doi: 10.1002/mds. 21510

Hackman, D. A., and Farah, M. J. (2009). Socioeconomic status and the developing brain. Trends Cogn. Sci. 13, 65-73. doi: 10.1016/j.tics.2008.11.003

Haddock, G., McCarron, J., Tarrier, N., and Faragher, E. B. (1999). Scales to measure dimensions of hallucinations and delusions: the psychotic symptom rating scales (PSYRATS). Psychol. Med. 29, 879-889. doi: 10.1017/S0033291799008661

Hammersley, P., Dias, A., Todd, G., Bowen-Jones, K., Reilly, B., and Bentall, R. P. (2003). Childhood trauma and hallucinations in bipolar affective disorder: a preliminary investigation. Br. J. Psychiatry 182, 543-547. doi: 10.1192/02-151

Healey, M. K., Campbell, K. L., and Hasher L. (2008). Cognitive aging and increased distractibility: costs and potential benefits. Prog. Brain Res. 169, 353-363. doi: 10.1016/S0079-6123(07)00022-2

Hoffman, R. E., Varanko, M., Gilmore, J., and Mishara, A. L. (2008). Experiential features used by patients with schizophrenia to differentiate 'voice' from ordinary verbal thought. Psychol. Med. 38, 1167-1176. doi: 10.1017/S0033291707002395

Howes, O. D., Bose, S. K., Turkheimer, F., Valli, I., Egerton, A., Valmaggia, L. R., et al. (2011). Dopamine synthesis capacity before onset of psychosis: a prospective [18]-DOPA PET imaging study. Am. J. Psychiatry 168, 1311-1317. doi: 10.1176/appi.ajp.2011.11010160

Howes, O. D., Kambeitz, J., Kim, E., Stahl, D., Slifstein, M., Abi-Dargham, A., et al. (2012). The nature of dopamine dysfunction in schizophrenia and what this means for treatment. Meta-analysis of imaging studies. Arch. Gen. Psychiatry 69, 776-786. doi: 10.1001/archgenpsychiatry.2012.169

Howes, O. D., and Kapur, S. (2009). The dopamine hypothesis of schizophrenia: version III-the final common pathway. Schizophr. Bull. 35, 549-562. doi: $10.1093 / \mathrm{schbul} / \mathrm{sbp} 006$

Howes, O. D., Montgomery, A. J., Asselin, M. C., Murray, R. M., Valli, I., Tabraham, P., et al. (2009). Elevated striatal dopamine function linked to prodromal signs of schizophrenia. Arch. Gen. Psychiatry 66, 13-20. doi: 10.1001/archgenpsychiatry.2008.514

Howes, O. D., Shotbolt, P., Bloomfield, M., Daalman, K., Demjaha, A., Diederen, K. M., et al. (2013). Dopaminergic function in the psychosis spectrum: an [18F]-DOPA imaging study in healthy individuals with auditory hallucinations. Schizophr. Bull. 39, 807-814. doi: 10.1093/schbul/ sbr195

Hugdahl, K., and Andersson, L. (1986). The "forced-attention paradigm" in dichotic listening to CV-syllables: a comparison between adults and children. Cortex 22, 417-432. doi: 10.1016/S0010-9452(86)80005-3

Hugdahl, K., Løberg, E.-M., Falkenberg, L. E., Johnsen, E., Kompus, K., Kroken, R., et al. (2012). Auditory verbal hallucinations in schizophrenia as aberrant lateralized speech perception: evidence from dichotic listening. Schizophr. Res. 140, 59-64. doi: 10.1016/j.schres.2012.06.019

Hugdahl, K., Løberg, E.-M., Jørgensen, H., Specht, K., Steen, V. M., Wageningen, H., et al. (2008). Auditory hallucinations in schizophrenia: the role of cognitive, brain structural and genetic disturbances in the left temporal lobe. Front. Hum. Neurosci. 1:6. doi: 10.3389/neuro.09/006

Hugdahl, K., Løberg, E. M., and Nygård, M. (2009b). Left temporal lobe structural and functional abnormality underlying auditory hallucinations in schizophrenia. Front. Neurosci. 3, 34-45. doi: 10.3389/neuro.01.001.2009

Hugdahl, K., Nygård, M., Falkenberg, L. E., Kompus, K., Westerhausen, R., Kroken, R., et al. (2013). Failure of attention focus and cognitive control in schizophrenia patients with auditory verbal hallucinations: evidence from dichotic listening. Schizophr. Res. 147, 301-309. doi: 10.1016/j.schres.2013.04.005

Hugdahl, K., Westerhausen, R., Alho, K., Medvedev, S., Laine, M., and Hämäläinen, H. (2009a). Attention and cognitive control: unfolding the dichotic listening story. Scand. J. Psychol. 50, 11-22. doi: 10.1111/j.1467-9450.2008.00676.x

Insel, T. (2013). "Transforming Diagnosis," The National Institute of Mental Health Director's BlogPosts. Available online at: http://www.nimh.nih.gov/about/director/2013/index.shtml

Insel, T. R., Cuthbert, B., Garvey, M., Heinssen, R., Pine, D. S., Quinn, K., et al. (2010). Research Domain Criteria (RDoC): towards a new classification framework for research on mental disorders. Am. J. Psychiatry 167, 748-751. doi: 10.1176/appi.ajp.2010.09091379

Jardri, R., Cachia, A., Thomas, P., and Pins, D. (2012). The Neuroscience of Hallucinations. New York, NY: Springer Science + Business Media.

Jardri, R., Pouchet, A., Pins, D., and Thomas, P. (2011). Cortical activations during auditory verbal hallucinations in schizophrenia: a coordinate-based metaanalysis. Am. J. Psychiatry 168, 73-81. doi: 10.1176/appi.ajp.2010.09101522

Jessop, M., Scott, J., and Nurcombe, B. (2008). Hallucinations in adolescent inpatients with post-traumatic stress disorder and schizophrenia: similarities and differences. Australas. Psychiatry 16, 268-272. doi: 10.1080/10398560801982580

Johnsen, E., Hugdahl, K., Fusar-Poli, P., Kroken, R. A., and Kompus, K. (2013). Neuropsychopharmacology of auditory hallucinations: insights from pharmacological MRI and perspectives for future research. Expert Rev. Neurother. 13, 23-36. doi: 10.1586/ern.12.147

Jung, W. H., Borgwardt, S., Fusar-Poli, P., and Kwon, S. J. (2012). Gray matter volumetric abnormalities associated with the onset of psychosis. Front. Psychiatry 3:101. doi: 10.3389/fpsyt.2012.00101

Kapur, S., and Mamo, D. (2003). Half a century of antipsychotics and still a central role for dopamine D2 receptors. Prog. Neuropsychopharmol. Biol. Psychiatry 27, 1081-1090. doi: 10.1016/j.pnpbp.2003.09.004

Kay, S. R., Fiszbein, A., and Opfer, L. A. (1987). The Positive and Negative Syndrome Scale (PANSS) for schizophrenia. Schizophr. Bull. 13, 261-276. doi: $10.1093 /$ schbul/13.2.261

Kaymaz, N., Drukker, M., Lieb, R., Wittchen, H. U., Werbeloff, N., Weiser, M., et al. (2012). Do subthreshold psychotic experiences predict clinical outcomes in unselected non-help-seeking population-based samples? A systematic review and meta-analysis, enriched with new results. Psychol. Med. 42, 2239-2253. doi: 10.1017/S0033291711002911

Kelleher, I., Connor, D., Clarke, M. C., Devlin, N., Harley, M., and Cannon, M. (2012a). Prevalence of psychotic symptoms in childhood and adolescence: a systematic review and meta-analysis of population-based studies. Psychol. Med. 42, 1857-1863. doi: 10.1017/S0033291711002960

Kelleher, I., Corcoran, P., Keeley, H., Wigman, J. T., Devlin, N., Ramsay, H., et al. (2013). Psychotic symptoms and population risk for suicide attempt: a prospective cohort study. JAMA Psychiatry 70, 940-948. doi: 10.1001/jamapsychiatry.2013.140

Kelleher, I., Keeley, H., Corcoran, P., Lynch, F., Fitzpatrick, C., Devlin, N., et al. (2012b). Clinico-pathological significance of psychotic symptoms in nonpsychotic young people: evidence from 4 population studies. Br. J. Psychiatry 201, 26-32. doi: 10.1192/bjp.bp.111.101543

Kompus, K., Westerhausen, R., and Hugdahl, K. (2011). The "paradoxical” engagement of the primary auditory cortex in patients with auditory verbal hallucinations: a meta-analysis of functional neuroimaging studies. Neuropsychologia 49, 3361-3369. doi: 10.1016/j.neuropsychologia.2011.08.010

Kringelbach, M. I. (2005). The human orbitofrontal cortex: linking reward to hedonic experience. Nat. Rev. Neurosci. 6, 691-702. doi: 10.1038/nrn1747

Kubota, M., Miyata, J., Sasamoto, A., Sugihara, G., Yoshida, H., Kawada, R., et al. (2012). Thalamocortical disconnection in the orbitofrontal region associated 
with cortical thinning in schizophrenia. JAMA Psychiatry 70, 12-21. doi: 10.1001/archgenpsychiatry.2012.1023

Laruelle, M., and Abi-Dargham, A. (1999). Dopamine as the wind of the psychotic fire: new evidence from brain imaging studies. J. Psychopharmacol. 13, 358-371. doi: 10.1177/026988119901300405

Laurens, K. R., Hobbs, M. J., Sunderland, M., Green, M. J., and Mould, G. L. (2012). Psychotic-like experiences in a community sample of 8000 children aged 9 to 11 years: an item response theory analysis. Psychol. Med. 42, 1495-1506. doi: $10.1017 /$ S0033291711002108

Linscott, R. J., and van Os, J. (2013). An updated and conservative systematic review and meta-analysis of epidemiological evidence on psychotic experiences in children and adults: on the pathway from proneness to persistence to dimensional expression across mental disorders. Psychol. Med. 43, 1133-1149. doi: 10.1017/S0033291712001626

Løberg, E. M., Hugdahl, K., and Green, M. F. (1999). Hemispheric asymmetry in schizophrenia: a "dual deficits" model. Biol. Psychiatry 45, 76-81. doi: 10.1016/S0006-3223(98)00219-4

Longden, E. (2010). Making sense of voices: a personal story of recovery. Psychosis 2, 255-259. doi: 10.1080/17522439.2010.512667

Luna, B., Padmanabhan, A., and O'Hearn, K. (2010). What has fMRI told us about the development of cognitive control through adolescence? Brain Cogn. 72, 101-113. doi: 10.1016/j.bandc.2009.08.005

Luna, B., Paulsen, D. J., Padmanabhan, A., and Geier, C. (2013). The teenage brain: cognitive control and motivation. Curr. Dir. Psychol. Sci. 22, 94-100. doi: $10.1177 / 0963721413478416$

Martinez, D., Orlowska, D., Narendran, R., Slifstein, M., Liu, F., Kumar, D., et al. (2010). Dopamine type $2 / 3$ receptor availability in the striatum and social status in human volunteers. Biol. Psychiatry 67, 275-278. doi: 10.1016/j.biopsych.2009.07.037

Matthys, W., Vanderschuren, L. J., and Schutter, D. J. (2013). The neurobiology of oppositional defiant disorder and conduct disorder: altered functioning in three mental domains. Dev. Psychopathol. 25, 193-207. doi: $10.1017 /$ S0954579412000272

McCarthy-Jones, S. (2013). Hearing Voices. The Histories, Causes and Meanings of Auditory Verbal Hallucinations. Cambridge, MA: Cambridge University Press.

Meads, D. M., and Bentall, R. P. (2008). Rasch analysis and item reduction of the hypomanic personality scale. Pers. Indiv. Differ. 44, 1772-1783. doi: 10.1016/j.paid.2008.02.009

Miller, E. K., and Cohen, J. D. (2001). An integrative theory of prefrontal cortex function. Annu. Rev. Neurosci. 24, 167-202. doi: 10.1146/annurev.neuro. 24.1.167

Moran, M. E., Hulshoff Pol, H., and Gogtay, N. (2013). A family affair: brain abnormalities in siblings of patients with schizophrenia. Brain 136, 3215-3226. doi: 10.1093/brain/awt116

Mullins, P. G., McGonigle, D. J., O'Gorman, R. L., Puts, N. A., Vidyasagar, R., Evans, C. J., et al. (2014). Current practice in the use of MEGAPRESS spectroscopy for the detection of GABA. Neuroimage 86, 43-52. doi: 10.1016/j.neuroimage.2012.12.004

National Institute of Mental Health. (2013). "The National Institute of Mental Health Strategic Plan." Available online at: http://www.nimh.nih.gov/ research-funding/rdoc/nimh-research-domain-criteria-rdoc.shtml

Nestor, P. G.,Nakamura, M., Niznikiewicz, M., Thompson, E., Levitt, J. J., Choate, V., et al. (2013). In search of the functional neuroanatomy of sociality: MRI subdivisions of orbital frontal cortex and social cognition. Soc. Cogn. Affect. Neurosci. 8, 460-467. doi: 10.1093/scan/nss018

Niendam, T. A., Laird, A. R., Ray, K. L., Dean, Y. M., Glahn, D. C., and Carter, C. S. (2012). Meta-analytic evidence for a superordinate cognitive control network subserving diverse executive function. Cogn. Affect. Behav. Neurosci. 12, 241-268. doi: 10.3758/s13415-011-0083-5

Paulik, G., Badcock, J. C., and Maybery, M. (2007). Poor intentional inhibition in individuals predisposed to hallucinations. Cogn. Neuropsychiatry 12, 457-470. doi: 10.1080/13546800701394329

Paulik, G., Badcock, J. C., and Maybery, M. (2008). Dissociating the components of inhibitory control involved in predisposition to hallucinations. Cogn. Neuropsychiatry 13, 33-46. doi: 10.1080./13546800701 775683

Pihan, H., Gutbrod, K., Baas, U., and Schnider, A. (2004). Dopamine inhibition and the adaptation of behaviour to ongoing reality. Neuroreport 15, 709-712. doi: 10.1097/00001756-200403220-00027
Puts, N. J. A., and Edden, R. A. E. (2012). In vivo magnetic resonance spectroscopy of GABA: a methodological review. Prog. Nucl. Magn. Reson. Spectrosc. 60, 29-41. doi: 10.1016/j.pnmrs.2011.06.001

Rossler, W., Hengartner, R. P., Ajdacic-Gross, V., Haker, H., Gamma, A., and Angst, J. (2011). Sub-clinical psychosis symptoms in young adults are risk factors for subsequent common mental disorders. Schizophr. Res. 131, 18-23. doi: 10.1016/j.schres.2011.06.019

Rossler, W., Riecher-Rossler, A., Angst, J., Murray, R., Gamma, A., Eich, D., et al. (2007). Psychotic experiences in the general population: a twenty-year prospective community study. Schizophr. Res. 92, 1-14. doi: 10.1016/j.schres.2007. 01.002

Sanjuan, J., Molto, M. D., and Tolosa, A. (2013). "Candidate genes in the expression of psychotic symptoms: a focus on hallucinations," in The Neuroscience of Hallucinations, eds R. Jardri, A. Cachia, P. Thomas, and D. Pins (New York, NY: Springer), 231-252.

Scarmeas, N., Brandt, J., Albert,M., Hadjigeorgiou, G., Papadimitriou, A., Dubois,B., et al. (2005). Delusions and hallucinations are associated with worse outcome in Alzheimer disease. Arch. Neurol. 62, 601-1608. doi: 10.1001/archneur.62.10.1601

Schnider, A. (2003). Spontaneous confabulations and the adaptation of thought to ongoing reality. Nat. Rev. Neurosci. 4, 662-671. doi: 10.1038/ nrn1179

Schnider, A. (2008). The Confabulating Mind. How the brain creates reality. Oxford: Oxford University Press. doi: 10.1093/med/9780199206759. 001.0001

Schnider, A. (2013). Orbitofrontal reality filtering. Front. Behav. Neurosci.7:67. doi: 10.3389/fnbeh.2013.00067

Schnider, A., Guggisberg, A., Nahum, D., Gabriel, D., and Morand, S. (2010). Dopaminergic modulation of rapid reality adaptation in thinking. Neuroscience 167, 583-587. doi: 10.1016/j.neuroscience.2010.02.044

Schnider, A., Treyer, V., and Buck, A. (2000). Selection of currently relevant memories by the human posterior medial orbitofrontal cortex. J. Neurosci. 20, 5880-5884.

Schroeder, K., Fisher, H. L., and Schafer, I. (2013). Psychotic symptoms in patients with borderline personality disorder: prevalence and clinical management. Curr. Opin. Psychiatry 26, 113-119. doi: 10.1097/YCO.0b013e32835a2ae7

Shinn, A. K., Pfaff, D., Young, S., Lewandowski, A. K., Cohen, B. M., and Ongür, D. (2012). Auditory hallucinations in a cross-diagnostic sample of psychotic disorder patients: a descriptive, cross-sectional study. Compr. Psychiatry 53, 718-726. doi: 10.1016/j.comppsych.2011.11.003

Silbersweig, D. A., Stern, E., Frith, C., Cahill, C., Holmes, A., Grootonk, S., et al. (1995). A functional neuroanatomy study of hallucinations in schizophrenia. Nature 378, 176-179. doi: 10.1038/378176a0

Slotema, C. W., Daalman, K., Blom,J. D., Diederen, K. M., Hoek, H. W., and Sommer, I. E. (2012). Auditory verbal hallucinations in patients with borderline personality disorder are similar to those in schizophrenia. Psychol. Med. 42, 1873-1878. doi: 10.1017/S0033291712000165

Soveri, A., Tallus, J., Laine, M., Nyberg, L., Bäckman, L.,Hugdahl, K., et al. (2013). Modulation of auditory attention by training: evidence from dichotic listening. Exp. Psychol. 60, 44-52. doi: 10.1027/1618-3169/a000172

Stephane, M. (2013). Auditory verbal hallucinations result from combinatoric associations of multiple neural events. Front. Hum.Neurosci. 7:239. doi: 10.3389/fnhum.2013.00239

Stokes, P. A., Shotbolt, P., Mehta, M. A., Turkheimer, E., Benecke,A., Copeland, C., et al. (2013). Nature or nurture? Determining the heritability of Human striatal dopamine function: an [18F]-DOPA PET study. Neuropsychopharmacology 38, 485-491. doi: 10.1038/npp.2012.207

Stroop, J. R. (1935). Studies of interference in serial verbal reactions. J. Exp. Psychol. 18, 643-662. doi: 10.1037/h0054651

Sun, J., Jayathilake, K., Zhao, Z., and Meltzer, H. (2012). Investigating association of four gene regions (GABRB3, MAOB, PAH, and SLC6A4) with five symptoms in schizophrenia. Psychiatry Res. 198, 202-206. doi: 10.1016/j.psychres.2011.12.035

Thomsen, T., Specht, K., Rimol, L. M., Hammar, Å.,Nyttingnes, J., Ersland, L., et al. (2004). Brain localization of attentional control in different age groups by combining functional and structural MRI. Neuroimage 22, 912-919. doi: 10.1016/j.neuroimage.2004.02.015

Turvey, C. L., Schultz, S. K., Arndt, S., Ellingrod, V., Wallace, R., and Herzog R. (2001). Caregiver report of hallucinations and paranoid delusions in elders 
aged 70 or older. Int. Psychogeriatr. 13, 241-249. doi: 10.1017/S1041610201 007621

van Rossum, I., Dominguez, M. D., Lieb, R., Wittchen, H. U., and van Os, J. (2011). Affective dysregulation and reality distortion: a 10-year prospective study of their association and clinical relevance. Schizophr. Bull. 37, 561-571. doi: 10.1093/schbul/sbp101

Varese, F., Barkus, E., and Bentall, R. P. (2012). Dissociation mediates the relationship between childhood trauma and hallucination-proneness. Psychol. Med. 42, 1025-1103. doi: 10.1017/S0033291711001826

Varghese, D., Scott, J., Welham, J., Bor, W., Najman, J., O’Callaghan, M., et al. (2011). Psychotic-like experiences in major depression and anxiety disorders: a population-based survey in young adults. Schizophr. Bull. 37, 389-393. doi: 10.1093/schbul/sbp083

Waters, F., Allen, P.,Aleman, A., Fernyhough, C., Woodward, T. S., Badcock, J. C., et al. (2012). Auditory hallucinations in schizophrenia and non-schizophrenia populations: a review and integrated model of cognitive mechanisms. Schizophr. Bull. 38, 683-693. doi: 10.1093/schbul/sbs045

Waters, F., Badcock, J. C., Maybery, M., and Michie, P. (2003). Inhibition in schizophrenia: association with auditory hallucinations. Schizophr. Res. 62, 275-280. doi: 10.1016/S0920-9964(02)00358-4

Whelan, R., Conrod, P. J., Poline, J.-P., Lourdusamy, A., Banaschewski, T., Barker, G. J., et al. (2012). Adolescent impulsivity phenotypes characterized by distinct brain networks. Nat. Neurosci. 15, 920-925. doi: 10.1038/nn.3092

Wigman, J. T., van Nierop, M., Vollebergh, W. A., Lieb, R., Beesdo-Baum, K., Wittchen, H. U., et al. (2012). Evidence that psychotic symptoms are prevalent in disorders of anxiety and depression, impacting on illness onset, risk, and severity: implications for diagnosis and ultra-high risk research. Schizophr. Bull. 38, 247-257. doi: 10.1093/schbul/sbr196

Wilson-Mendenhall, C. D., Feldman Barrett, L., and Barsalou, L. W. (2013). Neural evidence that human emotions share core affective properties. Psychol. Sci. 24, 947-956. doi: 10.1177/0956797612464242

Woodruff, P., Wright, I., Bullmore, E., Brammer, M., Howard, R., Williams, S. C., et al. (1997). Auditory hallucinations and the temporal cortical response to speech in schizophrenia: a functional magnetic resonance imaging study. Am. J. Psychiatry 154, 1676-1682.

Conflict of Interest Statement: The authors declare that the research was conducted in the absence of any commercial or financial relationships that could be construed as a potential conflict of interest.

Received: 01 February 2014; paper pending published: 03 March 2014; accepted: 10 March 2014; published online: 26 March 2014.

Citation: Badcock JC and Hugdahl K (2014) A synthesis of evidence on inhibitory control and auditory hallucinations based on the Research Domain Criteria (RDoC) framework. Front. Hum. Neurosci. 8:180. doi: 10.3389/fnhum.2014.00180

This article was submitted to the journal Frontiers in Human Neuroscience.

Copyright (c) 2014 Badcock and Hugdahl. This is an open-access article distributed under the terms of the Creative Commons Attribution License (CC BY). The use, distribution or reproduction in other forums is permitted, provided the original author(s) or licensor are credited and that the original publication in this journal is cited, in accordance with accepted academic practice. No use, distribution or reproduction is permitted which does not comply with these terms. 